\title{
PEMBUATAN ALAT PENDETEKSI API DAN ASAP BERBASIS MIKROKONTROLLER ARDUINO UNO DAN SENSOR MQ-2 KELUARAN SMS GATEWAY
}

\author{
Ikrar Nusa Bhakti Perwira ${ }^{\text {a) }}$, Wisnu Broto ${ }^{\mathrm{b})}$ \\ Universitas Pancasila Jakarta, Jurusan Teknik Elektro \\ Jl. Raya Lenteng Agung, Jagakarsa, Kota Jakarta Selatan, Daerah Khusus Ibukota Jakarta \\ Email: a)ikrarnusabhaktiperwira@yahoo.com, b)wisnu.agni@gmail.com
}

\begin{abstract}
Abstrak
Alat pendeteksi api merupakan suatu alat yang dapat mendeteksi adanya perubahan atau kenaikan temperature yang tidak normal dalam ruangan. Untuk mengatasi masalah kenaikan temperature yang signifikan, telah berhasil membuat model pendeteksi api berbasis arduino uno dan MQ-2 dengan keluaran berupa SMS gateway. Alat ini dilengkapi dengan 2 sensor yaitu sensor api infrared dan sensor asap MQ-2. Dalam percobaan dilakukan penelitian kepekaan pada sensor api infrared dengan bantuan alat Lux meter untuk mengukur intensitas cahaya pada sumber api. Percobaan ini menggunakan jarak untuk mengukur dan mengetahui kepekaan sensor api infrared dan Lux meter. Serta menggunakan 2 ilin sebagai sumber api dan jarak $10 \mathrm{~cm}$ sampai $110 \mathrm{~cm}$ dengan selisih $10 \mathrm{~cm}$. Percobaan pertama dengan Lux meter, besar intensitas cahaya yang di dapat pada jarak $10 \mathrm{~cm}$ adalah 132 lux. Jika jarak semakin jauh maka besar intensitas cahaya semakin turun, contoh jarak $110 \mathrm{~cm}$ dan $100 \mathrm{~cm}$ intensitas cahaya hanya 0 lux. Percobaan kedua dengan sensor api di dapatkan pada jarak $10 \mathrm{~cm}$ dengan sudut $0^{0}$ sampai jarak $90 \mathrm{~cm}$ sensor masih dapat mendeteksi api, tapi pada jarak $100 \mathrm{~cm}$ dan $110 \mathrm{~cm}$ sensor tidak bisa mendeteksi adanya api. Lalu pada sudut $30^{\circ}$ sampai $60^{\circ}$ sensor hanya dapat mendeteksi pada jarak $10 \mathrm{~cm}$.
\end{abstract}

Kata kunci: sensor api infrared, sensor asap MQ-2, arduino uno, lux meter, sms gateway

\section{PENDAHULUAN}

Bencana Kebakaran adalah suatu bencana yang sangat merugikan jika tidak cepat ditangani karena bencana ini dapat menghanguskan apapun yang kita miliki. Kebakaran dapat terjadi karena sumber api yang tidak kita ketahui seperti konsleting listrik, puntung rokok, meledaknya tabung gas, dan lain-lain. Api merupakan faktor utama penyebab terbesar terjadinya bencana kebakaran dan asap merupakan sebuah peringatan atau pemberitahuan bahwa bencana kebakaran sedang terjadi.

Tentunya pada suatu ruangan khusus sangat dibutuhkan adanya suatu alat keamanan yang fungsi utamanya untuk melindungi setiap orang di dalam ruangan tersebut dan untuk melindungi barang-barang yang sangat rentan terhadap api atau mudah terbakar. Contohnya pada sebuah laboratorium Teknik yang selalu digunakan untuk praktek dan di dalamnya terdapat alat-alat yang mudah terbakar. Untuk mengantisipasi masalah kebakaran tersebut sangat dibutuhkan alat pendeteksi api dan asap supaya terhindar oleh kebakaran tersebut. Pada Laboratorium Elektro Universitas Pancasila sering digunakan 
untuk praktek mahasiswa yang selalu mengkonsumsi energi listrik Untuk menajalankan alat-alat praktek. Alat-alat praktek tersebut biasanya mengkonsumsi energi listrik yang cukup besar dalam pemakainnya dan alat-alat ini digunakan setiap hari oleh mahasiswa semester awal maupun semester akhir. Oleh karena itu, telah dibuat alat pendeteksi api dan pendeteksi asap yang menggunakan sensor infrared dan sensor asap MQ-2 dengan keluaran atau output berupa SMS Gateway yang akan terkirim saat adanya api dan asap yang terdeteksi. Alat yang digunakan untuk output SMS gateway yaitu GSM Shield yang akan mengirimkan output SMS Gateway saat terdeteksi api dan asap. Tentunya GSM Shield ini saling terintegrasi dengan sensor lainnya pada saat terjadi kebakaran. Dengan adanya alat pendeteksi api dan asap berbasis mikokontroller arduino uno dan sensor MQ-2 ini, kita sudah melakukan langkah awal yang penting dalam menyelamatkan diri sendiri dan orang lain jika bencana kebakaran terjadi pada suatu ruangan yang kemungkinan besar dapat terjadi kebakaran.

\section{METODE PENELITIAN}

\section{Tahap Penentuan Masalah}

Kebakaran adalah suatu bencana yang disebabkan oleh api. Kebakaran bersifat menyebar luas keberbagaiarah dengan cara merambat pada medium atau benda yang dilaluinya kemudian memrambat lagi ke medium selanjutnya sampai membakar habis semuanya.

Dalam mengatasinya akan sangat sulit jika kita tidak bisa menemukan sumber api dari kebakaran tersebut. Jika tidak di padamkan dengan sesegera mungkin sumber api tersebut akan terus menjalar ke berbagai medium yang akan terus memperbesar kebakaran. Oleh karena itu, penelitian ini membuat sebuah model untuk mendeteksi sebuah asap dengan menggunakan sensor asap. Pendeteksian asap ini menggunakan mikrokontroler arduino uno sebagai pemroses rangkaian. Mikrokontroler merupakan keseluruhan sistem komputer yang dikemas menjadi sebuah chip di mana di dalamnya sudah terdapat mikroprosesor, I/O, memori bahkan ADC, berbeda dengan mikroprosesor yang berfungsi sebagai pemroses data Arduino UNO mempunyai 14 pin digital input/output (6 di antaranya dapat digunakan sebagai output PWM), 6 input analog, sebuah osilator Kristal 16 MHz, sebuah koneksi USB, sebuah power jack, sebuah ICSP header, dan sebuat tombol reset.

Pada Laboratorium Teknik Elektro Universitas Pancasila belum terdapat alat untuk mendeteksi adanya keberadaaan api dan asap yang kerap menimbulkan bencana kebakaran. Karena di laboratorium tersebut belum ada alat untuk mendeteksi adanya api dan asap maka sangat dibutuhkan alat pendeteksi yang dapat mengantisipasi bencana kebakaran sebelum semuanya terlambat dilahap oleh api yang sangat memungkinkan untuk merambat ke berbagai arah dan menyebabkan barang-barang terbakar habis. Karena di Laboratorium sensor ini sangat dibutuhkan untuk mencegah halhal yang tidak diinginkan. Sensor untuk mendeteksi adanya api salah satunya adalah sensor infrared, sensor ini mendeteksi cahaya dari suatu sumber api. Sedangkan sensor untuk mendeteksi keberadaan asap pada suatu rungan dapat digunakan dengan sensor MQ-2. Sensor MQ-2 digunakan karena sensor tersebut sangat sensitif dengan asap, selain sensitif dengan asap sensor MQ-2 juga sensitif dengan adanya gas.

\section{Tahap Analisi Masalah}

Masalah yang dihadapi sekarang adalah belum adanya alat pendeteksi sensor api dan sensor asap. Maka dari itu tujuan analisi ini yaitu untuk menganalisa masalah yang sedang dihadapi oleh laboratorium tersebut agar tidak akan terjadi musibah yang tidak di inginkan. Oleh karena itu dalam perakitan alat. Di rakitlah sebuah sensor yang mendeteksi keberadaan api pada suatu ruangan, sensor tersebut dapat digunakan dengan Infrared Flame Sensor. Alat ini bekerja jika terdapat asap pada suatu ruangan maka alat tersebut mengeluarkan bunyi atau alarm peringatan bahwa ada asap pada ruangan tersebut tapi jika adanya api maka secara otomatis alat akan menyemburkan air secara vertikal dari atas ke bawah untuk memadamkan api. 


\section{Analisis Kebutuhan}

1. ArduinoUno

Arduino Uno adalah papan pengembangan mikrokontroler yang berbasis chip ATmega328P. Disebut sebagai papan pengembangan karena board ini memang berfungsi sebagai arena prototyping sirkuit mikrokontroller. Dengan menggunakan papan pengembangan, anda akan lebih mudah merangkai rangkaian elektronika mikrokontroller dibanding jika anda memulai merakit ATMega328 dari awal di breadboard. Arduino Uno memiliki 14 digital pin input / output (atau biasa ditulis I/O, dimana 6 pin diantaranya dapat digunakan sebagai output PWM), 6 pin input analog, menggunakan crystal $16 \mathrm{MHz}$, koneksi USB, jack listrik, header ICSP dan tombol reset.

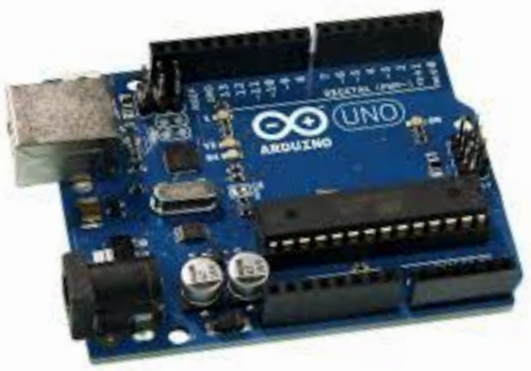

2. Sensor MQ-2 (Sensor Asap)

GAMBAR 1. Arduino uno

Sensor MQ-2 merupakan sensor yang digunakan untuk mendeteksi gas. Sensor gas dan asap ini mendeteksi konsentrasi gas yang mudah terbakar di udaraserta asap dan output membaca sebagai tegangan analog. Jika terdapat kebocoran gas konduktifitas sensor menjadi lebih tinggi, setiap kenaikan konsentrasi gas maka konduktifitas sensor juga naik. MQ-2 sensitif terhadap gas LPG, Propana, Hidrogen, Karbon Monoksida, Metana dan Alkohol. Sensor dapat mengukur konsentrasi gas mudah terbakar dari 300 ppm sampai 10.000 ppm [5]. Dapat beroperasi pada suhu dari -20 sampai 50 ${ }^{\circ} \mathrm{C}$ dan mengkonsumsi kurang dari $150 \mathrm{~mA}$ pada 5V [6]. Berikut dibawah ini adalah gambar Module Sensor MQ-2 dapat dilihat Gambar 2.

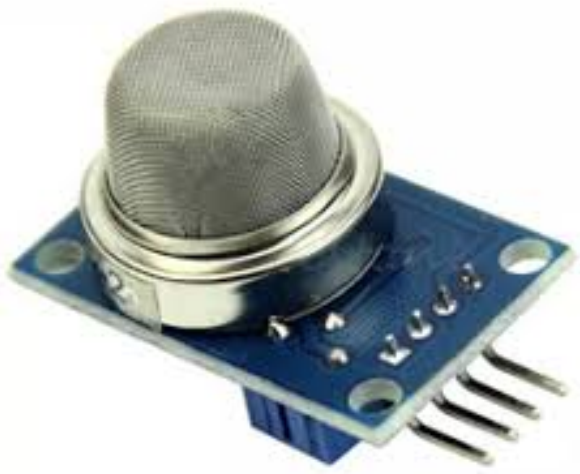

3. Sensor Api

GAMBAR 2. Sensor MQ-2

Flame detectors atau sensor api merupakan sensor yang digunakan untuk mendeteksi keberadaan api. Sensor ini mampu mendeteksi posisi nyala api dengan ketelitian tinggi (hingga nyala api sekecil cahaya lain). Pada sensor ini terdapat sebuah sensor photodioda yang digunakan untuk mendeteksi adanya mata api disekitar sensor tersebut. Sensor ini terdapat 4 pin yaitu pin GND, VCC, Digital Output, dan Analog Output. Walaupun yang digunakan pada alat ini hanya 3 pin saja yaitu GND, VCC, dan Analog Output. Terdapat juga sebuah potensiometer untuk mengatur keluaran yang dihasilkan pada sensor tersebut. Pada module sensor ini juga menggunakan IC LM393. 


\section{GSM Shield SIM900}

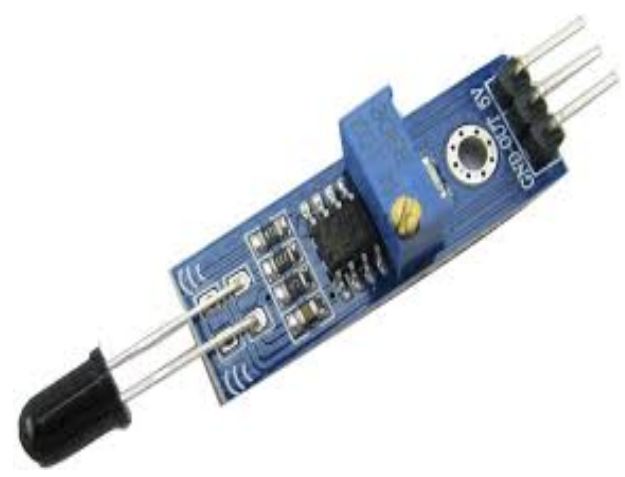

Arduino GSM Shield adalah sebuah board yang dirancang terintegrasi dengan arduino dengan fungsi untuk dapat mengirim sms, membuat voice call atau mengkoneksi internet dengan menggunakan wireless network. GPRS Shield digunakan sebagai piranti untuk melakukan komunikasi melalui SMS antara Arduino dengan HP User, maupun sebaliknya [7]. SMS (Short Message Service) adalah kemampuan untuk mengirim dan menerima pesan dalam bentuk teks dari dan kepada ponsel [8]. GSM Shield adalah sebuah board yang berguna sebagai mengirim sebuah SMS dari alat tersebut ke pengguna. Cara menggunakan GSM Shield ini hanya tinggal dicolokkan pada board arduino uno yang digunakan. Untuk dapat terhubung ke arduino dan berjalan dengan baik maka pin RX pada GSM Shield dipasang dengan pin TX pada arduino uno tersebut. GSM-GPRS Shield dikonfigurasi dan dikendalikan melalui UART dengan menggunakan simple AT command, dilihat pada Gambar 3.

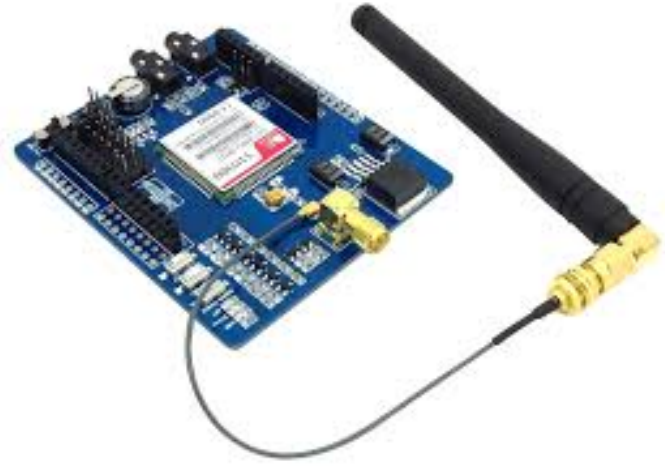

GAMBAR 4. GSM Shield sim900

\section{Perancangan Alat}

Pada tahapan ini adalah tahapan membuat alur dan cara kerja dengan mnggunakan aplikasi berupa software Visio. Flowchart dibuat supaya mempermudah pengerjaan saat proses pembuatan alat tersebut dan output yang dihasilkan akan sesuai dengan harapan. Karena flowchart ini sangat penting untuk cara kerja alat. dari proses input sampai output dari alat tersebut. Lihat pada Gambar 5. 


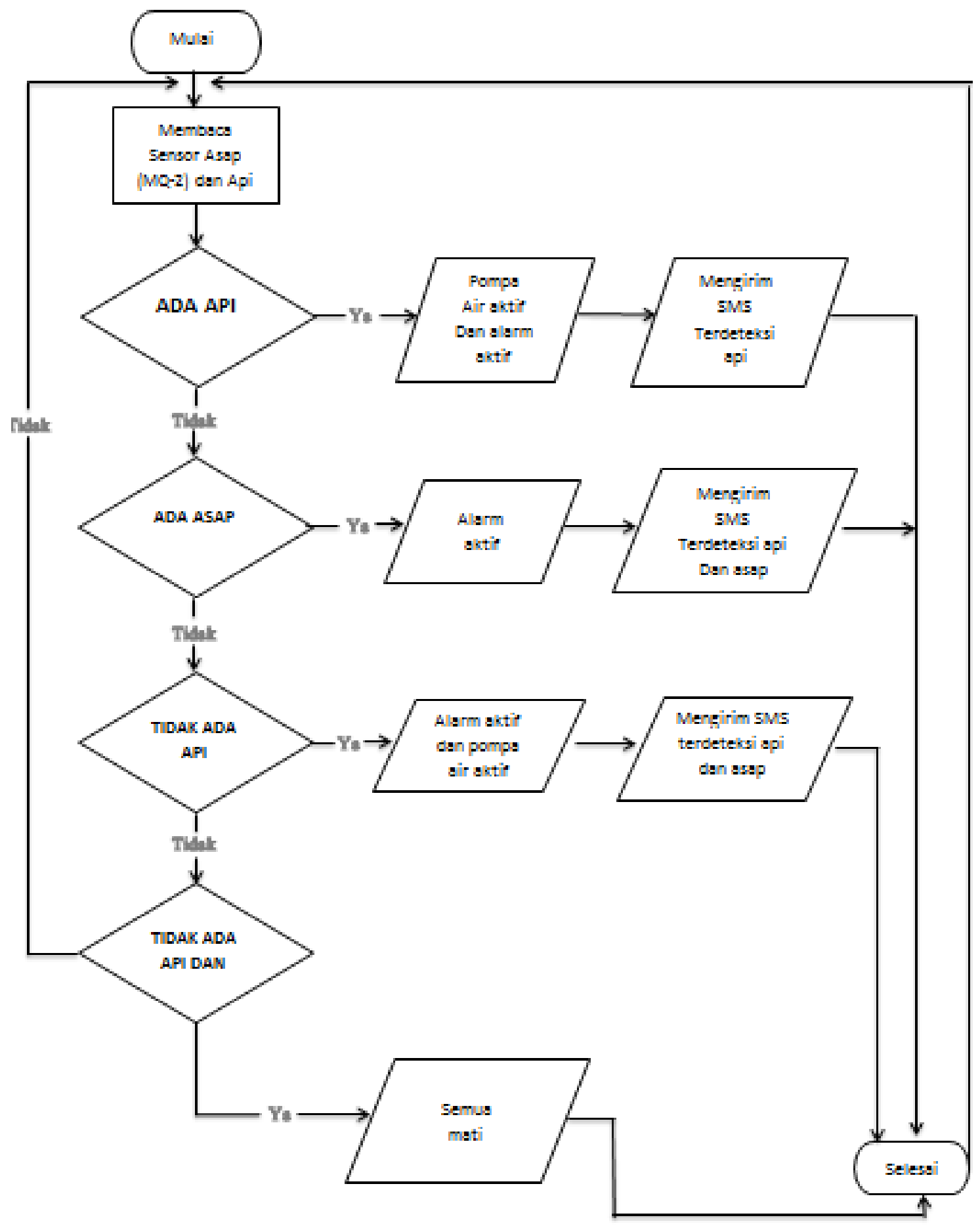

GAMBAR 5. Flowchart

Pembuatan Alat

Pada tahap ini akan di paparkan gambar skema rangkaian yang akan menampilkan model alat dari gabungan sensor-sensor. Tahap ini merupakan tahap yang menghabiskan waktu cukup lama untuk menyelesaikannya karena pada tahap ini adalah proses awal perakitan alat serta membuat casing untuk menjaga alat tersebut dari hal-hal yang tak diinginkan. Selain itu, tahap ini juga membuat sebuah kode 
program supaya alat tersebut berjalan dengan baik dan sesuai harapan. Kode program yang dibuat adalah sesuai dengan flowchart yang telah dibuat dalam tahap perancangan alat. Tahap ini juga membuat skema rangkain dengan bantuan aplikasi yaitu Fritzing. Lihat pada Gambar 6.

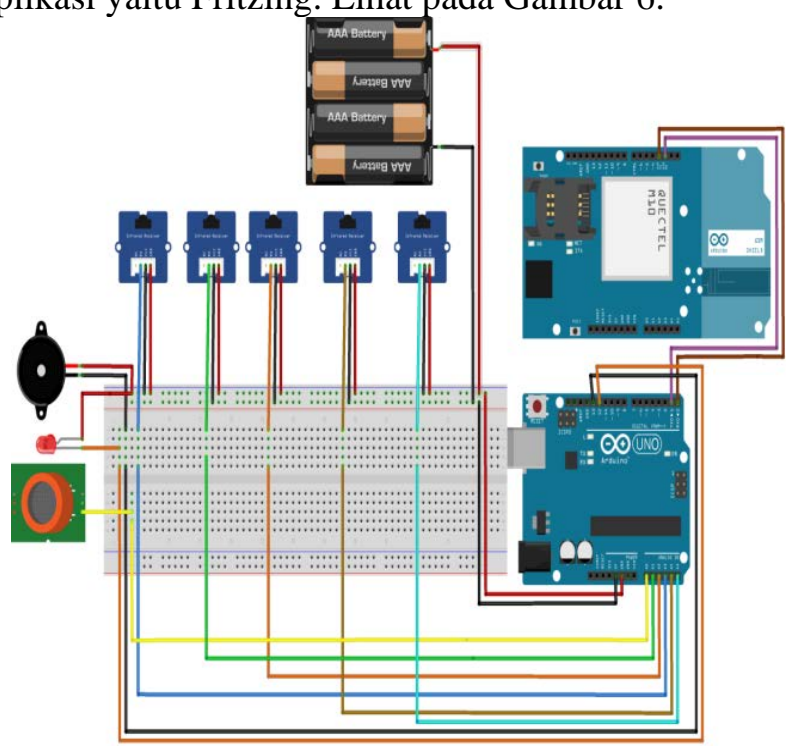

GAMBAR 6. Skema Rangkaian

\section{Simulasi Alat}

Pada tahap simulasi prototipe adalah tahap dilakukannya simulasi atau uji coba terhadap alat yang sudah dibuat. Tujuannya adalah untuk mendapatkan informasi kekurangan yang ada dari solusi yang diberikan. Simulasi tersebut langsung menguji alat ini.

\section{HASIL DAN PEMBAHASAN}

\section{Data Lux Meter}

Pengambilan data pada Lux Meter menggunakan sumber cahaya yaitu 2 buah lilin yang disejajarkan. Jarak diukur dengan alat meteran, jarak dimulai dari $10 \mathrm{~cm}$ sampai dengan $110 \mathrm{~cm}$ dengan selisih jarak yaitu per $10 \mathrm{~cm}$. Data yang didapat adalah jika Lux Meter dijauhkan dengan sumber cahaya tersebut maka Lux yang didapatkan akan semakin berkurang ini dikarenakan dari sumber tersebut akan memancarkan sebuah cahaya dan jika jarak tersebut semakin jauh maka cahaya tersebut akan semakin redup. Lihat pada Tabel 1.

Tabel 1. Tabel dan Lux Meter

\begin{tabular}{ccc}
\hline \multicolumn{3}{c}{ Tabel Lux Meter } \\
\hline NO & Jarak $(\mathrm{cm})$ & Lux \\
\hline 1 & 10 & 132 \\
2 & 20 & 49 \\
3 & 30 & 18 \\
4 & 40 & 10 \\
5 & 50 & 6 \\
6 & 60 & 4 \\
7 & 70 & 2 \\
8 & 80 & 2 \\
9 & 90 & 1 \\
10 & 100 & 0 \\
11 & 110 & 0 \\
\hline
\end{tabular}




\section{Data Sensor Api}

TABEL 2. Data Sensor Api

\begin{tabular}{|c|c|c|c|c|c|c|c|c|}
\hline \multirow{3}{*}{ No } & \multirow{3}{*}{ Jarak } & \multicolumn{7}{|c|}{ Sudut } \\
\hline & & \multirow{2}{*}{$0^{0}$} & \multicolumn{2}{|c|}{$30^{0}$} & \multicolumn{2}{|c|}{$45^{0}$} & \multicolumn{2}{|c|}{$60^{0}$} \\
\hline & & & Kanan $(+)$ & Kiri (-) & Kanan (+) & Kiri (-) & Kanan (+) & Kiri (-) \\
\hline 1 & 10 & ON & ON & ON & ON & ON & ON & ON \\
\hline 2 & 20 & ON & ON & ON & OHF & OHF & OFF & OHF \\
\hline 3 & 30 & ON & OFF & OFF & OFF & OFF & OFF & OFF \\
\hline 4 & 40 & ON & OFF & OFF & OFF & OFF & OFF & OFF \\
\hline 5 & 50 & ON & OFF & OFF & OFF & OFF & OFF & OFF \\
\hline 6 & 60 & ON & OFF & OFF & OFF & OFF & OFF & OFF \\
\hline 7 & 70 & ON & OFF & OFF & OFF & OFF & OFF & OFF \\
\hline 8 & 80 & ON & OГГ & ОГГ & ОГГ & OГГ & OFT & ОГГ \\
\hline 9 & 90 & ON & OFF & OFF & OFF & OFF & OFF & OFF \\
\hline 10 & 100 & OFF & OFF & OFF & OFF & OFF & OFF & OFF \\
\hline 11 & 110 & OFF & OFF & OFF & OFF & OFF & OFF & OFF \\
\hline
\end{tabular}

Pengambilan data dengan sensor api ini sama halnya dengan menggunakan Lux Meter, sumber api yang digunakan sama yaitu menggunakan 2 buah lilin yang disejajarkan yang berbeda hanya pada jaraknya yaitu ditambahkan sudut-sudut untuk mengetahui kepekaan dari sensor tersebut. Data yang didapatkan bahwa pada sudut $0^{0}$ dengan jarak $10 \mathrm{~cm}$ sampai dengan $90 \mathrm{~cm}$ sensor masih dapat membaca inputan tetapi pada jarak $1 \mathrm{~m}$ lebih sensor sudah tidak dapat membaca inputan. Berbeda dengan sudut $30^{\circ}$, $45^{\circ}$, dan $60^{\circ}$ sensor hanya dapat membaca inputan pada jarak $\pm 10 \mathrm{~cm}$ sampai dengan $20 \mathrm{~cm}$. Jika lebih dari jarak $20 \mathrm{~cm}$ sensor sudah tidak dapat membaca dari inputan. Pada Tabel 2 menunjukkan data yang dihasilkan pada pengujian sensor api.

\section{Uji Coba Menggunakan SMS (Short Message Service)}

Pada Tahap uji Coba Menggunakan SMS, merupakan tahapan untuk menguji model alat yang akan mengeluarkan output berupa SMS. Berikut adalah output dari SMS tersebut saat mendeteksi api dapat dilihat pada Gambar 6, saat mendeteksi asap dapat dilihat pada Gambar 7, sedangkan saat terdeteksi api dan asap dapat dilihat pada Gambar 8.

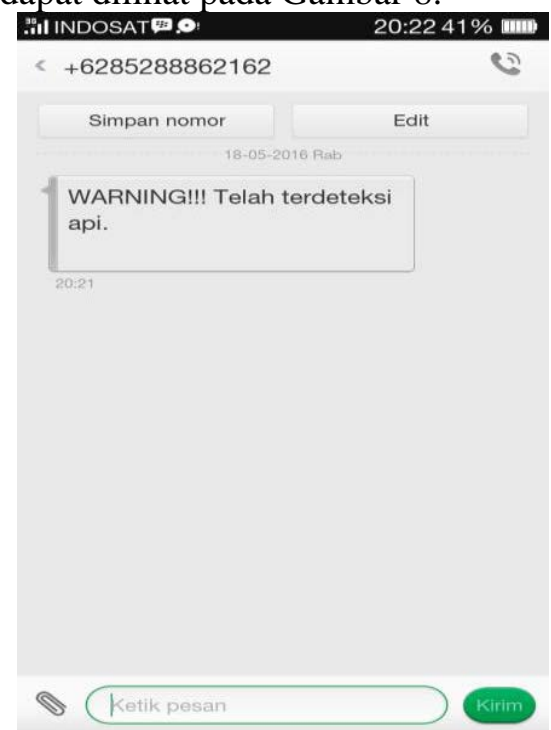

GAMBAR 6. Output SMS Saat Mendeteksi Api

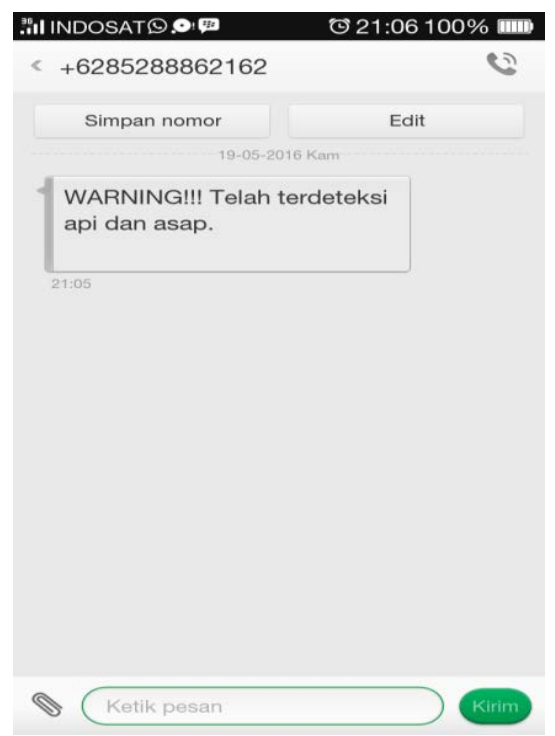

GAMBAR 7. Output SMS Saat Mendeteksi Asap 


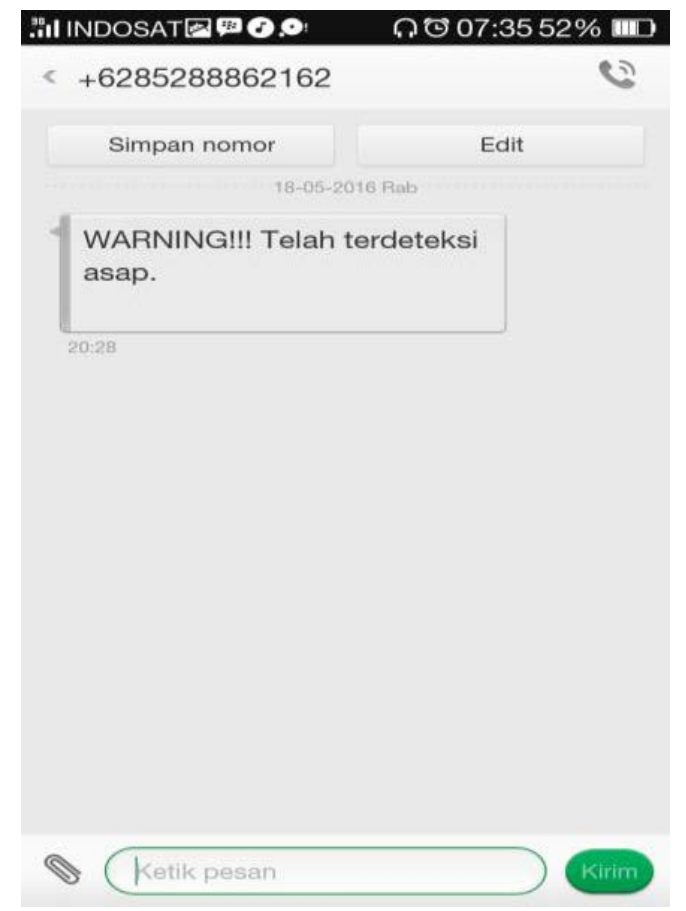

GAMBAR 8. Output SMS Saat Mendeteksi Api dan Asap

\section{SIMPULAN}

Telah berhasil membuat alat pendeteksi api dan asap berbasis mikrokontroller arduino undo dan sensor MQ-2 dengan keluaran SMS Gateway. ketika terdeteksi api maka alarm peringatan pun berbunyi dan relay akan aktif yang tersambung dengan pompa air tersebut yang ditaruh pada penampungan air, lalu akan mengeluarkan air untuk memadamkan api tersebut, selain itu mengirim sebuah SMS peringatan bahwa terdeteksi adanya api. Jika terdeteksi asap hanya alarm peringatan yang aktif dan uga mengirim sebuah SMS peringatan bahwa terdeteksi adanya asap. Dari tahap simulasi alat, data yang telah didapatkan bahwa sensor api yang digunakan tidak begitu sensitif. Sensor api tersebut sensitif hanya pada jarak dari $10 \mathrm{~cm}$ sampai $90 \mathrm{~cm}$, sedangkan pada jarak satu meter sensor tersebut sudah tidak sensitif. Sensor api lebih sensitif pada sudut 00 atau berhadapan lurus dengan sumber api daripada dengan sudutsudut lainnya. Pada dasarnya sistem pengukuran sensor api dengan lux meter sama saja. Jika pada lux meter, semakin jauh jarak antara alat lux meter dengan sumber api maka semakin kecil hasil Lux yang dihasilkan dari alat lux meter tersebut. Contoh ini membuktikan bahwa sistem pengukuran sensor api dengan lux meter sama saja.

\section{UCAPAN TERIMAKASIH}

Terimakasih banyak kepada pembimbing saya, Wisnu Broto, ST.MT yang telah membantu selama membuat serta mengerjakan makalah full paper dari alat pendeteksi api dan asap berbasi mikrokontroller arduino uno dan MQ-2. Serta saya ucapkan terimakasih kepada teman yang telah membantu dalam diskusi untuk mengerjakan alat ini dengan baik dan cermat. Saya ucapkan terimakasih banyak kepada partisipan yang telah membantu saya dalam pengerjaan makalah full paper ini.

\section{REFERENSI}

[1] A. Mandagi, dan Stheven Immanuel, "Penggunaan Sensor Gas MQ-2 Sebagai Pendeteksi Asap Rokok”, vol. 3 no. 9, pp. 1-7, 2014. 
[2] A. Adriansyah dan O. Hidyatama, "Rancang Bangung Prototipe Elevator Menggunakan Microcontroller Arduino Atmega 328P”, vol. 4 no.3, pp. 120-132, 2013.

[3] Datasheet Sensor MQ-2.

[4] P. Siagian dan E. Fernando, "Sistem Informasi Penerimaan Mahasiswa Baru Dengan SMS Gateway”, vol. 6 no. 1, pp. 679-685, 2014.

[5] A.S Tsauri, E.P Nugroho, dan Y. Wibisono, "Pengembangan Model Sistem Elearning Komunitas Dengan Pendekatan Personal Learning Environments”, vol. 2 no. 2, pp. 25-32, 2009.

[6] D.K. Fisher, and H. Kebede, "A Low-Cost Microcontroller-Based System to Monitor Crop Temperature and Water Status”, vol. 76, pp. 168-173, 2010.

[7] A. Adriansyah, dan O. Hidyatama, "Rancang Bangung Prototipe Elevator Menggunakan Microcontroller Arduino Atmega 328P”, vol. 4 no. 3, pp. 120-132, 2013.I 
